\title{
PENGARUH BERBAGAI JENIS UMPAN TERHADAP TRAP SUCCESS DALAM PENGENDALIAN PES (Studi di Dusun Surorowo, Desa Kayukebek, Kecamatan Tutur, Kabupaten Pasuruan Tahun 2017)
}

Maria Ajeng Kinanti, Sri Mardoyo, Ernita Sari

\begin{abstract}
ABSTRAK
Dusun Surorowo merupakan daerah fokus penyakit Pes di Pasuruan yang masih perlu dilakukan pengawasan. Kepadatan pinjal dan tikus dapat berpengaruh terhadap penularan penyakit pes karena pinjal berperan sebagai vektor penyakit pes sedangkan tikus sebagai reservoir penyakit ini. Selain itu, masih adanya tersangka penyakit Pes di daerah tersebut perlu dilakukan upaya kewaspadaan dini seperti pengendalian populasi tikus, salah satunya yaitu dengan melakukan pemasangan perangkap. Faktor utama yang menentukan keberhasilan penangkapan tikus atau trap success yaitu jenis umpan yang digunakan. Tujuan penelitian ini adalah agar mengetahui pengaruh dari berbagai jenis umpan terhadap angka keberhasilan penangkapan tikus dalam pengendalian pes.

Jenis penelitian ini adalah penelitian eksperimen semu (quasi eksperimental research), dengan rancangan penelitian yang digunakan yaitu Posttest Only Design karena peneliti mengukur pengaruh perlakuan atau (intervensi) pada kelompok eksperimen dan dalam penelitian tidak dilakukan pretest. Selain itu, dalam penelitian ini tidak ada kontrol. Penelitian dilakukan di Dusun Surorowo, Desa Kayukebek, Kecamatan Tutur, Kabupaten Pasuruan pada bulan Maret sampai Juli Tahun 2017.

Hasil penelitian adalah umpan yang paling berpengaruh terhadap trap success adalah umpan jagung manis dimana terdapat 106 ekor tikus tertangkap dengan prosentase tikus yang tertangkap sebesar $10,9 \%$. Trap success paling tinggi yaitu umpan jagung manis dengan nilai trap success rata - rata 16,67 \% dalam rumah, 6,67 \% di kebun, 9,6 \% di hutan. Jenis tikus yang tertangkap yaitu Rattus tanezumi, Rattus exulans, Rattus tiomanicus, dan Hylomys suillus. Angka kepadatan pinjal atau indeks pinjal umum dalam rumah sebesar 3,16 sedangkan indeks pinjal khusus 2,69. Indeks pinjal umum di kebun sebesar 0,61 sedangkan indeks pinjal khusus 0,22. Indeks pinjal umum di hutan sebesar 1,13 sedangkan indeks pinjal khusus 0,4 dengan jenis pinjal yang teridentifikasi yaitu Xenopsylla cheopis dan Stivalius cognatus. Dari hasil penelitian yang dilakukan, disarankan umpan yang digunakan dalam penangkapan tikus adalah jagung manis.
\end{abstract}

Kata Kunci : Umpan, Trap Success, Pes

\section{PENDAHULUAN}

Pes atau sampar adalah salah satu penyakit zoonosa terutama pada tikus atau rodent yang ditularkan kepada manusia. Penyakit ini disebabkan oleh bakteri Yersinia pestis atau Pasteurella pestis melalui gigitan pinjal (Xenopsylla cheopis) yang merupakan vektor penyakit ini (Balai Litbang Pengendalian Penyakit Bersumber Binatang, 2011). Akhir tahun 1986 terjadi wabah Pes di wilayah Nongkojajar tepatnya di Dusun Surorowo, Desa Kayukebek, Kecamatan Tutur Kabupaten Pasuruan Jawa Timur. Setelah dilakukan surveillance dan trapping dari Direktorat Jenderal Pengendalian Penyakit dan Penyehatan Lingkungan ternyata didapatkan tikus yang positif Pes.
Sejak tahun 1987 wilayah Nongkojajar Pasuruan ditetapkan sebagai daerah fokus Pes, artinya daerah tersebut harus diawasi dan dilakukan sistem kewaspadaan dini supaya tidak lagi terjadi KLB Pes (Direktorat Jenderal Pengendalian Penyakit dan Penyehatan Lingkungan, 2014).

Setelah tahun 1987, terjadi kembali KLB 13 orang suspect di tahun 1997. Tahun 2007 di wilayah Nongkojajar, khususnya Dusun Surorowo tercatat bahwa terdapat satu warga yang penderita penyakit Pes dan tahun 2013 tercatat masih ada suspect Pes di daerah tersebut. Kegiatan pengamatan di daerah fokus harus selalu dilakukan secara terus menerus terhadap manusia dan binatang. Upaya pencegahan 
penyebaran dan penularan penyakit Pes dapat dilakukan dengan pelaksanaan pengendalian jumlah tikus yang menjadi reservoir utama dalam penularan Pes (Direktorat Jenderal Pengendalian Penyakit dan Penyehatan Lingkungan, 2014).

Salah satu pengendalian tikus yaitu dengan pengendalian secara fisik / mekanik dengan pemasangan perangkap hidup yang nantinya trap success dapat dihitung untuk melihat tingkat keberhasilan penangkapan tikus. Trap success dapat dijadikan sebagai tolok ukur dalam perhitungan kepadatan tikus. Salahsatu faktor utama yang sangat berpengaruh terhadap keberhasilan penangkapan tikus (trap success) yaitu umpan yang digunakan. Sebelum dilakukan pemasangan perangkap tikus untuk pengendalian penyakit Pes perlu dilakukan prebaiting atau pengujian berbagai jenis umpan. Menurut Khoirul, 2016 belum pernah dilakukan pre-baiting di Dusun Surorowo.

Tikus menyukai makanan yang beraroma kuat atau menyengat dan menyukai biji - bijian. Menurut WHO, kelapa bakar merupakan standar untuk menjadi umpan perangkap tikus karena kelapa bakar menarik perhatian tikus dari baunya yang menyengat. Ikan asap merupakan ikan yang diawetkan dengan cara pengasapan dimana ikan asap memiliki aroma yang kuat dan menyengat. Jagung manis merupakan tanaman palawija dan merupakan salah satu tanaman biji - bijian serta cukup mudah ditemukan di lokasi penelitian. Maka dari itu peneliti menggunakan umpan kelapa bakar, ikan asap, dan jagung manis.

\section{METODE PENELITIAN}

Penelitian ini merupakan penelitian eksperimen semu (quasi eksperimental research) dengan desain penelitian Posttest Only Design. Obyek penelitian ini adalah tikus di daerah Dusun Surorowo yang merupakan salah satu daerah fokus Pes di Nongkojajar yang masih berpotensi menimbulkan wabah.

\section{HASIL DAN PEMBAHASAN \\ Jumlah Tikus yang Tertangkap}

Trapping yang pertama dalam penelitian ini dilakukan pada tanggal 20 Maret - 25 Maret 2017 dimana jumlah tikus tertangkap sebanyak 36 ekor. Trapping yang kedua dilakukan pada tanggal 17 April - 22 April 2017 dimana jumlah tikus tertangkap sebanyak 46 ekor. Trapping yang ketiga dilakukan pada tanggal 29 Mei - 3 Juni 2017 dimana jumlah tikus tertangkap sebanyak 51 ekor. Penjabarannya dapat dilihat pada Tabel 1 berikut

Tabel 1

JUMLAH TIKUS TERTANGKAP KESELURUHAN

\begin{tabular}{|c|c|c|c|c|c|c|}
\hline \multirow[b]{2}{*}{$\begin{array}{c}\text { Lokasi } \\
\text { No. }\end{array}$} & \multirow[b]{2}{*}{ Trapping ke- } & \multirow[b]{2}{*}{$\begin{array}{c}\text { Pemasangan } \\
\text { Perangkap }\end{array}$} & \multicolumn{3}{|c|}{ Jenis Umpan } & \multirow[b]{2}{*}{ Jumlah } \\
\hline & & & $\begin{array}{l}\text { Kelapa } \\
\text { Bakar }\end{array}$ & $\begin{array}{l}\text { Ikan } \\
\text { Asap }\end{array}$ & $\begin{array}{l}\text { Jagung } \\
\text { Manis }\end{array}$ & \\
\hline \multirow{3}{*}{1.} & \multirow{3}{*}{ I } & Rumah & 1 & 1 & 9 & 11 \\
\hline & & Kebun & 0 & 0 & 10 & 10 \\
\hline & & Hutan & 5 & 0 & 10 & 15 \\
\hline \multirow{3}{*}{2.} & \multirow{3}{*}{ II } & Rumah & 6 & 2 & 22 & 30 \\
\hline & & Kebun & 0 & 0 & 5 & 5 \\
\hline & & Hutan & 5 & 0 & 6 & 11 \\
\hline \multirow{3}{*}{3.} & \multirow{3}{*}{ III } & Rumah & 3 & 1 & 19 & 23 \\
\hline & & Kebun & 1 & 0 & 7 & 8 \\
\hline & & Hutan & 2 & 0 & 18 & 20 \\
\hline \multicolumn{3}{|c|}{ Jumlah } & 23 & 4 & 106 & 133 \\
\hline \multicolumn{3}{|c|}{$\begin{array}{l}\text { Berdasarkan Tabel } 1 \text { menunjukkan } \\
\text { bahwa umpan yang paling banyak tikus } \\
\text { tertangkap yaitu umpan jagung manis } \\
\text { sebanyak } 106 \text { ekor dimana } 50 \text { ekor } \\
\text { tertangkap di dalam rumah, } 22 \text { ekor }\end{array}$} & \multicolumn{4}{|c|}{$\begin{array}{l}\text { tertangkap di kebun, dan } 34 \text { ekor } \\
\text { tertangkap di hutan. Umpan kelapa } \\
\text { bakar sebanyak } 23 \text { ekor dimana } 10 \text { ekor } \\
\text { tertangkap di rumah, } 1 \text { ekor tertangkap } \\
\text { di kebun, dan } 12 \text { ekor di hutan. Tikus }\end{array}$} \\
\hline
\end{tabular}


yang tertangkap pada umpan ikan asap sebanyak 4 ekor tikus di dalam rumah.

\section{Trap success}

Tingkat keberhasilan penangkapan tikus atau trap success keseluruhan menggambarkan jumlah tikus tertangkap dibanding dengan jumlah perangkap yang dipasang. Penjabarannya dapat dilihat pada Tabel 2 berikut :

Tabel 2

TRAP SUCCESS KESELURUHAN

\begin{tabular}{cccc}
\hline No. & Trapping ke- & Trap success \\
\hline 1. & I & $3,6 \%$ \\
\hline 2. & II & $4,6 \%$ \\
\hline 3. & III & $5,1 \%$ \\
\hline & Rata - rata & & $4,43 \%$
\end{tabular}

Berdasarkan Tabel 2, menunjukkan bahwa trap success pada trapping pertama sebesar $3,6 \%$, trap success pada trapping kedua sebesar $4,6 \%$, dan trap success pada trapping ketiga sebesar $5,1 \%$ dan rata - rata trap success keseluruhan yaitu 4,43\%. Selain itu, trap success dapat dihitung sesuai lokasi penangkapan dan masing - masing umpan. Penjabarannya dapat dilihat pada Tabel 3 dan tabel 4 berikut:

Tabel 3

TRAP SUCCESS BERDASARKAN JENIS UMPAN

\begin{tabular}{|c|c|c|c|c|}
\hline Trapping ke- & $\begin{array}{l}\text { Jenis } \\
\text { Umpan }\end{array}$ & $\begin{array}{c}\text { Lokasi Pemasangan } \\
\text { Perangkap }\end{array}$ & Trap succoss & Total \\
\hline \multirow{9}{*}{1} & \multirow{3}{*}{ Kelapa Bakar } & Rumah & $1 \%$ & \multirow{3}{*}{$1,7 \%$} \\
\hline & & Kebun & $0 \%$ & \\
\hline & & Hutan & $3,33 \%$ & \\
\hline & \multirow{3}{*}{ Ikan Asap } & Rumah & $1 \%$ & \multirow{3}{*}{$0,3 \%$} \\
\hline & & Kebun & $0 \%$ & \\
\hline & & Hutan & $0 \%$ & \\
\hline & \multirow{3}{*}{$\begin{array}{l}\text { Jagung } \\
\text { Manis }\end{array}$} & Rumah & $9 \%$ & \multirow{3}{*}{$8,9 \%$} \\
\hline & & Kebun & $10 \%$ & \\
\hline & & Hutan & $8 \%$ & \\
\hline II & Kelapa Bakar & Rumah & $6 \%$ & $3,1 \%$ \\
\hline & & Kebun & $2 \%$ & \\
\hline & & Hutan & $2 \%$ & \\
\hline & \multirow{3}{*}{ Ikan Asap } & Rumah & $2 \%$ & \multirow{3}{*}{$0,6 \%$} \\
\hline & & Kebun & $0 \%$ & \\
\hline & & Hutan & $0 \%$ & \\
\hline & \multirow{3}{*}{$\begin{array}{l}\text { Jagung } \\
\text { Manis }\end{array}$} & Rumah & $22 \%$ & \multirow{3}{*}{$10,2 \%$} \\
\hline & & Kebun & $3 \%$ & \\
\hline & & Hutan & $6,4 \%$ & \\
\hline \multirow{9}{*}{ III } & \multirow{3}{*}{ Kelapa Bakar } & Rumah & $3 \%$ & \multirow{3}{*}{$1,71 \%$} \\
\hline & & Kebun & $1 \%$ & \\
\hline & & Hutan & $1,33 \%$ & \\
\hline & \multirow{3}{*}{ Ikan Asap } & Rumah & $1 \%$ & \multirow{3}{*}{$0,31 \%$} \\
\hline & & Kebun & $0 \%$ & \\
\hline & & Hutan & $0 \%$ & \\
\hline & \multirow{3}{*}{$\begin{array}{l}\text { Jagung } \\
\text { Manis }\end{array}$} & Rumah & $19 \%$ & \multirow{3}{*}{$13,54 \%$} \\
\hline & & Kebun & $7 \%$ & \\
\hline & & Hutan & $14,4 \%$ & \\
\hline
\end{tabular}


Tabel 4

RATA - RATA TRAP SUCCESS KESELURUHAN

\begin{tabular}{ccccc}
\hline \multirow{2}{*}{ No. } & Jenis Umpan & \multicolumn{3}{c}{ Trap success } \\
\cline { 3 - 5 } & & Rumah & Kebun & Hutan \\
\hline 1. & Kelapa Bakar & $3,33 \%$ & $1 \%$ & $2,22 \%$ \\
\hline 2. & Ikan Asap & $1,33 \%$ & $0 \%$ & $0 \%$ \\
\hline 3. & Jagung Manis & $16,67 \%$ & $6,67 \%$ & $9,6 \%$ \\
\hline
\end{tabular}

Berdasarkan Tabel 3 dan Tabel 4 menunjukkan bahwa trap success paling tinggi yaitu umpan jagung manis dengan nilai trap success rata - rata $16,67 \%$ dalam rumah, $6,67 \%$ di kebun, 9,6\% di hutan. Kemudian nilai trap success umpan kelapa bakar dalam rumah sebesar $3,33 \%$, di kebun $1 \%$, dan di hutan 2,22 \%. Umpan ikan asap yang paling rendah yaitu 1,33 \% dalam rumah dan 0 untuk kebun serta hutan.

\section{Analisis Pengaruh Jenis Umpan terhadap Jumlah Tikus Tertangkap dan Trap Success}

Data hasil penelitian diolah dengan analisis statistik Chi square, untuk mengetahui seberapa besar proporsi jumlah tikus yang tertangkap berdasarkan jenis umpan dengan perangkap yang negatif tikus. Tabel hasil analisa terdapat di Lampiran 1 yang menggambarkan proporsi perangkap masing - masing umpan yang positif tikus. Diketahui bahwa nilai Asymp. Sig (2 - sided) yaitu 0,000 lebih kecil dari $\mathrm{p}<$ value 0,05 artinya ketiga jenis umpan menghasilkan jumlah tikus tertangkap yang berbeda secara analisis statistik.

\section{Jenis Tikus yang Tertangkap}

Tikus yang tertangkap dapat dibedakan atau diidentifikasi sesuai dengan jenisnya. Penjabarannya dapat dilihat pada Tabel 5.

Tabel 5

JENIS TIKUS TERTANGKAP KESELURUHAN

\begin{tabular}{|c|c|c|c|c|c|}
\hline $\begin{array}{c}\text { Lokasi } \\
\text { Pemasanga } \\
\text { tiomanicus }\end{array}$ & Ratt & $\begin{array}{l}\text { Tik } \\
\text { Hylo }\end{array}$ & grta & ext & Tota \\
\hline Rumah & 61 & 3 & 0 & 0 & 64 \\
\hline Kebun & 4 & 19 & 0 & 0 & 23 \\
\hline Hutan & 7 & 28 & 9 & 2 & 46 \\
\hline Total & 72 & 50 & 9 & 2 & 133 \\
\hline
\end{tabular}

Berdasarkan Tabel 5 menunjukkan bahwa setelah pelaksanaan trapping pertama, kedua, dan ketiga jenis tikus yang paling banyak tertangkap di dalam rumah adalah Rattus tanezumi sebesar 61 ekor, kemudian Rattus exulans sebanyak 3 ekor. Jenis tikus yang paling banyak tertangkap di kebun adalah Rattus exulans sebanyak 19 ekor, kemudian Rattus tanezumi sebanyak 4 ekor. Jenis tikus yang paling banyak tertangkap di hutan yaitu Rattus exulans sebanyak 289 ekor, Rattus tanezumi sebanyak 7 ekor, dan Hylomys suillus sebanyak 2 ekor.

\section{Jenis Pinjal dan Angka Kepadatan Pinjal}

Tikus yang tertangkap disisir untuk mengetahui ada tidaknya pinjal tikus kemudian diidentifikasi jenisnya. Jenis pinjal yang ditemukan dikelompokkan sesuai jenis tikus yang tertangkap. Hasil identifikasi pinjal pelaksanaan trapping pertama hingga ketiga dapat dilihat pada tabel 6 dan 7.

Berdasarkan Tabel V.6 dan Tabel V.7 dapat diketahui bahwa jumlah pinjal selama ketiga trapping sebanyak 268 ekor. Jenis pinjal yang paling banyak di tubuh Rattus tanezumi adalah 
Xenopsylla cheopis sebanyak 174 ekor, sedangkan Stivalius cognatus sebanyak 35 ekor. Jenis pinjal yang paling banyak di tubuh Rattus exulans adalah Stivalius cognatus sebanyak 33 ekor, sedangkan Xenopsylla cheopis sebanyak 14 ekor.
Jenis pinjal yang paling banyak ditemukan di tubuh Rattus tiomanicus adalah Xenopsylla cheopis sebanyak 8 ekor dan Stivalius cognatus sebanyak 4 ekor.

Tabel 6

JENIS PINJAL

\begin{tabular}{|c|c|c|c|c|}
\hline \multirow{2}{*}{$\begin{array}{c}\text { Trapping } \\
\text { ke- }\end{array}$} & \multirow[b]{2}{*}{ Jenis Tikus } & \multicolumn{2}{|c|}{ Jenis Pinjal } & \multirow[b]{2}{*}{ Total } \\
\hline & & \multicolumn{2}{|c|}{ Stivalius cognatus Xenopsylla cheopis } & \\
\hline \multirow{4}{*}{ I } & Rattus tanezumi & 22 & 133 & 155 \\
\hline & Rattus exulans & 21 & 6 & 27 \\
\hline & Rattus tiomanicus & 0 & 0 & 0 \\
\hline & Hylomys suillus & 0 & 0 & 0 \\
\hline \multirow{4}{*}{ II } & Rattus tanezumi & 3 & 21 & 24 \\
\hline & Rattus exulans & 7 & 5 & 12 \\
\hline & Rattus tiomanicus & 4 & 8 & 12 \\
\hline & Hylomys suillus & 0 & 0 & 0 \\
\hline \multirow{4}{*}{ III } & Rattus tanezumi & 10 & 20 & 30 \\
\hline & Rattus exulans & 5 & 3 & 8 \\
\hline & Rattus tiomanicus & 0 & 0 & 0 \\
\hline & Hylomys suillus & 0 & 0 & 0 \\
\hline & & 72 & 196 & 268 \\
\hline
\end{tabular}

Tabel 7

JENIS PINJAL KESELURUHAN

Jenis Pinjal

\begin{tabular}{|c|c|c|c|}
\hline \multirow[b]{2}{*}{ Jenis Tikus } & \multicolumn{2}{|c|}{ Jenis Pinjal } & \multirow[b]{2}{*}{ Total } \\
\hline & Stivalius cognatus & Xenopsylla cheopis & \\
\hline Rattus tanezumi & 35 & 174 & 209 \\
\hline Rattus exulans & 33 & 14 & 47 \\
\hline $\begin{array}{c}\text { Rattus } \\
\text { tiomanicus }\end{array}$ & 4 & 8 & 12 \\
\hline Hylomys suillus & 0 & 0 & 0 \\
\hline
\end{tabular}

Setelah jenis pinjal teridentifikasi, dapat menghitung angka kepadatan pinjal atau indeks pinjal dari semua tikus yang tertangkap. Penjabarannya dapat dilihat pada Tabel 8 dan Tabel 9.
Berdasarkan Tabel 8 dan Tabel 9 diketahui bahwa indeks pinjal umum dalam rumah sebesar 3,16 sedangkan indeks pinjal khusus 2,69. Indeks pinjal umum di kebun sebesar 0,61 sedangkan 
indeks pinjal khusus 0,22 . Indeks pinjal umum di hutan sebesar 1,13 sedangkan indeks

pinjal khusus

0,41 .

Tabel 8

INDEKS PINJAL

\begin{tabular}{ccccccc}
\hline Trapping ke- & Lokasi & $\begin{array}{c}\text { Jumlah Pinjal } \\
\text { Stivalius } \\
\text { cognatus }\end{array}$ & $\begin{array}{c}\text { Jumlah Pinjal } \\
\text { Xenopsylla } \\
\text { cheopis }\end{array}$ & $\begin{array}{c}\text { Indeks } \\
\text { Pinjal } \\
\text { Umum }\end{array}$ & $\begin{array}{c}\text { Indeks } \\
\text { Pinjal } \\
\text { Khusus }\end{array}$ \\
\hline \multirow{2}{*}{ I } & Rumah & 22 & 136 & 14,36 & 12,36 \\
\cline { 2 - 7 } & Kebun & 5 & 1 & 0,6 & 0,1 \\
\hline \multirow{2}{*}{ II } & Hutan & 16 & 2 & 1,2 & 0,17 \\
\hline \multirow{2}{*}{ III } & Rumah & 3 & 21 & 0,8 & 0,7 \\
\hline & Kebun & 4 & 3 & 1,4 & 0,6 \\
\hline & Hutan & 7 & 10 & 1,5 & 0,9 \\
\hline & Rumah & 5 & 15 & 0,87 & 0,65 \\
\hline & Kebun & 0 & 1 & 0,13 & 0,13 \\
\hline
\end{tabular}

Tabel 9

RATA - RATA INDEKS PINJAL KESELURUHAN

\begin{tabular}{ccccc}
\hline Lokasi & $\begin{array}{c}\text { Jumlah Pinjal } \\
\text { Stivalius } \\
\text { cognatus }\end{array}$ & $\begin{array}{c}\text { Jumlah Pinjal } \\
\text { Xenopsylla } \\
\text { cheopis }\end{array}$ & $\begin{array}{c}\text { Indeks Pinjal } \\
\text { Umum }\end{array}$ & $\begin{array}{c}\text { Indeks } \\
\text { Pinjal } \\
\text { Khusus }\end{array}$ \\
\hline Rumah & 30 & 172 & 3,16 & 2,69 \\
\hline Kebun & 9 & 5 & 0,61 & 0,22 \\
\hline Hutan & 33 & 19 & 1,13 & 0,41 \\
\hline
\end{tabular}

\section{KESIMPULAN DAN SARAN}

\section{Kesimpulan}

a. Prosentase tikus yang tertangkap dengan umpan kelapa bakar sebesar $2,2 \%$ dengan jumlah tikus yang tertangkap sebanyak 23 ekor, untuk ikan asap sebesar 0,4\% dengan jumlah tikus yang etrtangkap sebanyak 4 ekor, sedangkan prosentase tikus yang tertangkap dengan umpan jagung manis sebesar $10,9 \%$ dengan jumlah tikus yang tertangkap sebanyak 106 ekor.

b. Trap success paling tinggi yaitu umpan jagung manis dengan nilai trap success rata - rata $16,67 \%$ dalam rumah, $6,67 \%$ di kebun, $9,6 \%$ di hutan. Kemudian nilai trap success umpan kelapa bakar dalam rumah sebesar 3,33\%, di kebun $1 \%$, dan di hutan $2,22 \%$. Umpan ikan asap yang paling rendah yaitu $1,33 \%$ dalam rumah dan 0 untuk kebun serta hutan.

c. Umpan jagung sangat berpengaruh dalam trap success dan dapat digunakan dalam penangkapan tikus yang merupakan salah pengendalian penyakit Pes.

d. Ada 4 jenis tikus yang tertangkap saat penelitian yaitu Rattus tanezumi, Rattus exulans, Rattus tiomanicus dan Hylomys suillus.

e. Ada 2 jenis pinjal yang ditemukan saat penelitian yaitu Xenopsylla cheopis dan Stivalius cognatus.

f. Indeks pinjal umum dalam rumah sebesar 3,16 sedangkan indeks pinjal khusus 2,69. Indeks pinjal umum di kebun sebesar 0,61 sedangkan indeks pinjal khusus 0,22. Indeks pinjal umum di hutan sebesar 1,13 sedangkan indeks pinjal khusus 0,41. 


\section{Saran}

a. Bagi Puskesmas Nongkojajar Sesuai dengan hasil penelitian ini, sebaiknya umpan yang digunakan dalam penangkapan tikus atau trapping adalah umpan jagung manis agar bisa lebih memaksimalkan program pengendalian penyakit Pes.

b. Masyarakat

Disarankan masyarakat semakin mendukung program dinas kesehatan serta ikut membantu dalam pengendalian pes misalnya dengan mau melakukan trapping mandiri.

c. Bagi Peneliti Lain

Perlu dilakukan penelitian lanjutan mengenai pemetaan penyebaran penyakit Pes di daerah Nongkojajar.

\section{DAFTAR PUSTAKA}

Balai Litbang Pengendalian Penyakit Bersumber Binatang, 2011. Buku Saku Mengenal Penyakit Pes / Plague. Banjarnegara : Kementrian Kesehatan Republik Indonesia.

$\begin{array}{lrr}\text { Direktorat } & \text { Jenderal } & \text { Pengendalian } \\ \text { Penyakit } & \text { dan } & \text { Penyehatan } \\ \text { Lingkungan, } & 2014 . & \text { Petunjuk } \\ \text { Pengendalian } & \text { Pes. } & \text { Jakarta, } \\ \text { Kementrian } & \text { Kesehatan } & \text { Republik } \\ \text { Indonesia. } & & \end{array}$

Khoirul, Ahmad, 2016. Evaluasi Keberhasilan Penangkapan Tikus (Trap Success) Dan Indeks Pinjal (Studi Di Desa Kayukebek Kecamatan Tutur Kabupaten Pasuruan. Surabaya, Kesehatan Lingkungan Surabaya Politeknik Kesehatan Kementrian Kesehatan Surabaya.

Notoatmodjo, Soekidjo, 2014. Metodologi Penelitian Kesehatan (Edisi Revisi). Jakarta : Rineka Cipta. 